\title{
ESTRUCTURACIÓN DEL PERÍODO EN EL QUIJOTE
}

1.

La estructuración de la oración simple en las lenguas románicas ha sido bien estudiada y desde mucho tiempo. El motivo principal será, quizás, el hecho de que la norma válida para el latín literario no haya sido heredada por las lenguas románicas; estas han adoptado el esquema "sujeto-verbo-objeto".

Como el pensamiento humano, enunciandum para el lingüista, no se concluye, por lo general, en la oración simple, podemos considerar como unidad mínima del habla el período u oración compuesta y preguntarnos sobre su estructuración; sería necesario examinar si el orden de los elementos de la oración compuesta está condicionado por reglas o tendencias que parecen lógicas. Igual, como se observa en la oración simple donde al sujeto estả reservado el puesto inicial y a los complementos los detrás del verbo.

Las gramáticas del español hablan muy poco del problema, mientras para el latín se encuentra un análisis breve, pero exhaustivo en la gran gramática latina del Szantyr. ${ }^{1}$

Simplificando, se podría reducir la presentación de la norma en dos tendencias: precede a la principal, mejor dicho, subordinante, la subordinada que anuncia, motiva, condiciona (o impide), causa, en cierto sentido prepara la realización de la acción expresada por la subordinante, o que expresa una acción cronológicamente anterior, mientras le sigue cuando expresa el objeto de la actividad, fin, consecuencia o comparación.

Está fuera de nuestro interés, aquí, la subordinada relativa, es decir la que se refiere a un elemento de la oración subordinante, ya sea especificativa, Los gobiernos insulanos no son todos de buena data [...] el más erguido y bien dispuesto trae consigo una pesada carga de pensamientos y de incomodidades, que pone sobre sus hombros el desdichado que le cupe en suerte (II,13), o explicativa, En un lugar de la Mancha, de cuyo nombre no quiero acordarme $(\mathrm{I}, 1)$.

2.

Lo expuesto no está contradicho por los pasos cervantinos. ${ }^{2}$ Cierto, trátase de tendencias y no de reglas fijas. Constata ya Meyer-Lübke ${ }^{3}$ para el español, en manera especial para el español arcaico, la casi imposibilidad de establecer una regla: la colocación de

1 V. Leumann-Hofmann-Szantyr, Lateinische Grammatik, 2-Syntax und Stilistik, München, 1965, p. 733 y ss.

2 Las citas según Miguel de Cervantes, El ingenioso hidalgo don Quijote de la Mancha, Colección Austral, $33^{\mathrm{a}}$ edición, Madrid, Espasa-Calpe, 1985.

3 W. Meyer-Lübke, Grammatik der Romanischen Sprachen, III-Syntax, Leipzig, 1892, pág. 805. 
las partes de la oración simple y compuesta es bastante libre, es decir, el que habla o escribe maneja los elementos de la oración según su momentánea disposición psíquica. Meyer-Lübke da ejemplos también del Quijote (además de pasos, para el español preclásico, de Amadís): No le pareció mal al barbero la invención (I,27); y, por la oración compuesta: Apenas hubo salido de la venta, cuando le vino al cura un pensamiento $(I, 27)$. Respecto a otras grandes lenguas románicas le parece a Meyer-Lübke que el español es la menos sujeta a la norma.

Con todo, una norma, siempre para la estructuración de la oración compuesta, parece ser respetada por el autor del Quijote, la de posponer la subordinada de complemento directo: No estaban ociosas la sobrina y el ama de don Quijote, que por mil señales iban coligiendo que su tio y señor quería desgarrarse la vez tercera $(\mathrm{II}, 6)$; Yo así lo creo respondió Sancho-, y querría que vuesa merced me dijese qué es la causa porque dicen los españoles cuando quieren dar alguna batalla... (II,58).

Sigue igualmente la subordinada de complemento directo cuando es sustancialmente una interrogativa indirecta: Preguntóle si traía dineros (I,3); Quisiera que me hicieran sabidora si está en este gremio, corrro y compañía, el acendradísimo caballero don Quijote (II,38). De las adverbiales siguen la final y la consecutiva: En resolución, él se enfrascó tanto en su lectura, que se le pasaban las noches leyendo de claro en claro, y los dias de turbio en turbio; así, del poco dormir y del mucho leer se le secó el cerebro de manera que vino a perder el juicio (I,1); $A$ ti digo, joh sol, con cuya ayuda el hombre engendra al hombre! a ti digo que me favorezcas, y alumbres la escuridad de mi ingenio, para que pueda discurrir por sus puntos en la narración del gobierno del gran Sancho Panza (II,45); Bajó el gobernador la vara, y en tanto, el viejo del báculo dió el báculo al otro viejo, que se le tuviese en tanto que juraba (II,45).

Es también lógico que una modal o una comparativa siguen a la subordinante; si no fuese así, la comparación no sería posible: Vístanme - dijo Sancho-como quisieren; que de cualquier manera que vaya vestido, seré Sancho Panza $(\mathrm{II}, 42)$; Este mal hombre me ha cogido en la mitad dese campo, y se ha aprovechado de mi cuerpo, como si fuera trapo mal lavado (II ,45); Sin osar decir lo que el hombre tiene en su corazón, como si fuera mudo (I,25); De cualquiera palabra que Sancho decía la Duquesa gustaba tanto como se desesperaba don Quijote (II,39).

3.

Al contrario, la subordinada condicional precede a la subordinante: Si acaso doblares la vara de la justicia, no sea con el peso de la dádiva, sino con el de la misericordia (II,42); Porque si vuelves presto de adonde pienso enviarte, presto se acabará mi pena $(I, 25)$. Precede también la concesiva: Por mucho cuidado que pongan y habilidad que muestren (los traductores), jamás llegarán al punto que ellos tienen en su primer nacimiento $(I, 6)$. Siempre, pero, cuando la idea expresada por una condicional o concesiva parece bastante independiente, es decir que las dos oraciones no forman una rigurosa unidad (del tipo "condición-realización") la posición de la subordinada es libre, no es fija; depende de la intuición del hablante: Llévenme a mi lecho, y llámese, si fuere posible, a la sabia Urganda (I,5); Y sin duda alguna lo hiciera, y aun saliera con ello, si 
otros mayores y continuos pensamientos no se lo estorbaran $(\mathrm{I}, 1)$; Quieren decir que tenía el sobrenombre de Quijada, o Quesada, que en esto hay alguna diferencia en los autores que deste caso escriben; aunque por conjeturas verosimiles se deja entender que se llamaba Quijana (ibid.); Que con esta carga nacemos las mujeres, de estar obedientes a sus maridos, aunque sean unos porros (II,5). Talvez, como en el paso del I, 1, la puntuación indica la independencia de la subordinada. Sería el caso de preguntarse sobre los límites entre la coordinación y subordinación.

Las temporales preceden, en la mayoría de los casos, la subordinante cuando se expresa una acción o un estado anteriores a la situación de la principal: Mas apenas se vió en el campo, cuando le asaltó un pensamiento terrible $(\mathrm{I}, 2)$; el empleo de la conjunción temporal en las dos oraciones no es rara en Cervantes, cf. el paso citado por MeyerLübke. En general influye la sucesión cronológica: Había de llevar armas blancas, como novel caballero, sin empresa en el escudo, hasta que por su esfuerzo la ganase (ibid.); No me levantaré jamás de donde estoy, valeroso caballero, fasta que la vuestra cortesía me otorgue un don que pedirle quiero $(\mathrm{I}, 3)$.

4.

Nos interesa en modo particular la posición de la subordinada subjetiva, no fuese que por el hecho indiscutible que tal subordinada es el sujeto del período y el sujeto, en la oración simple, de regla ocupa el primer puesto. Una prueba la ofrecen también los proverbios que, como se sabe, en El Quijote abundan: Antes he yo oído decir - dijo don Quijote-que quien canta, sus males espanta (I,22); Quien está ausente todos los malos teme $(\mathrm{I}, 25)$. Encontramos la subordinada sujeto al puesto inicial también fuera de los proverbios: Porque quien oyere decir a vuestra merced que una bacía de barbero es el yelmo de Mambrino [...] ¿qué ha de pensar sino que quien tal dice y afirma debe de tener güero el juicio? (I,25); Retencio es - respondió Sancho-que quien está en el infierno nunca sale dél $(\mathrm{I}, 25)$. No ocurre diferentemente hasta en los casos donde se constata un anacoluto, cf. el proverbio: "Quien madruga, Dios le ayuda".

Pero, cuando la subordinada sujeto tiene como predicado un verbo impersonal o atributivo el predicado ocupa el primer puesto y la supuesta subordinada sujeto le sigue. Verbos que aparecen como predicado o parte del predicado son sobretodo ser, estar, haber (hay, había etc.) parecer, bastar: Y fue que le pareció convenible y necesario [...] hacerse caballero andante (I,1); Es verdad que para probar si era fuerte y podía estar al riesgo de una cuchillada, sacó su espada y le dió dos golpes (ibid.). Y fue que le vino a la memoria que no era armado caballero (I,2); Es que el anduvo todo aquel día (ibid.); $Y$ fuera mejor que se curara $(\mathrm{I}, 3)$; Habláis de tan rodeada manera, que no hay quien os entienda (II,5); Ten por cierto, Teresa, que no habrá quien se acuerde de lo que fue (ibid.); Que me parece que te despeñas de la alta cumbre de tu locura hasta el profundo abismo de tu simplicidad (II, 1); Basta que en la narración del no se salga un punto de la verdad $(\mathrm{I}, 1)$; Basta que me entienda Dios (II,5). Conviene repetir que no se trata de una regla fija, sino de una tendencia. Nos ocupamos sólo de la subordinada explícita; las implícitas siguen a la principal, menos en pasos estilísticos: esta sí que es una regla fija. 
Puede concluirse que una subordinada sujeto precede al predicado cuando representa un verdadero sujeto, cuando la función del sujeto es sentida. Le sigue, al contrario, cuando con un verbo unipersonal o atributivo hace parte integrante del predicado.

\section{Povzetek}

\section{UREJANJE PRVIN POVEDI V CERVANTESOVEM DON KIHOTU}

Besedni red $\mathrm{v}$ prostem stavku je $\mathrm{v}$ španščini manj tog, kot je sicer $\mathrm{v}$ romanskih jezikih. Najbolj pogostna struktura prostega stavka je osebek-povedek-predmet. Zato lahko pričakujemo, da bo nekako logično utemeljeno tudi razvrščanje odvisnikov $\mathrm{v}$ povedi, v zloženem stavku.

In res ugotavljamo v Cervantesovem Don Kihotu, razen kadar gre za očitne zahteve stila, dokaj ustaljeno rabo: pred povedkom stojijo tisti odvisniki, ki realizacijo nadrednega, glavnega stavka časovno napovedujejo, jo omogočajo (ali preprečujejo), jo pogojujejo; sledijo pa povedku tisti, ki izražajo predmet, cilj, namen glagolskega dejanja, ali posledico le-tega ali tudi primerjalno prvino. Posebej so zanimivi osebkovi odvisniki: stojijo pred povedkom, če je odvisnik resničen osebek, in stojijo za povedkom, če je odvisnik tesno vezan na povedek, tako zlasti pri brezosebnih glagolih, kadar torej gre za povedkov odvisnik. 